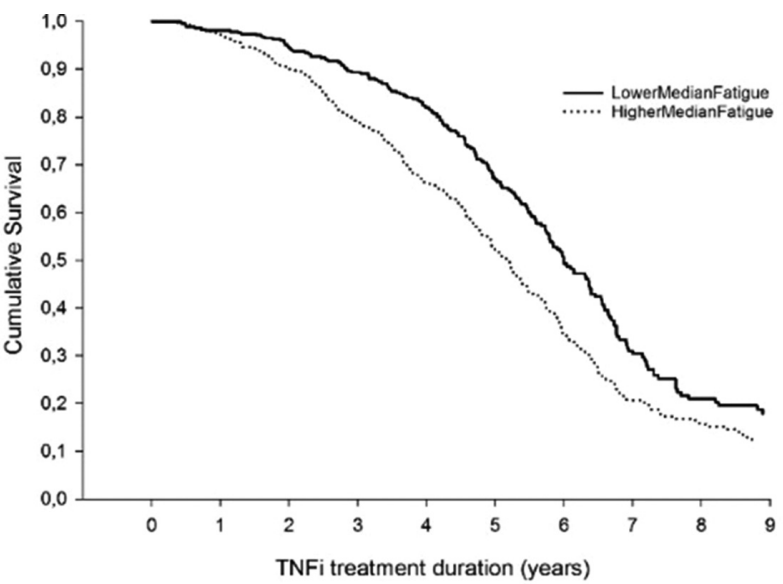

$\begin{array}{lcccccccccc}\text { Years of TNFi treatment } & 0 & \mathbf{1} & \mathbf{2} & \mathbf{3} & \mathbf{4} & \mathbf{5} & \mathbf{6} & \mathbf{7} & \mathbf{8} & \mathbf{9} \\ \text { LowerMedianfatigue (n) } & 430 & 387 & 337 & 283 & 238 & 166 & 94 & 47 & 28 & 19\end{array}$

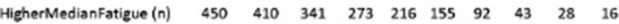

Conclusions: Fatigue remains a dominating symptom after TNFi treatment, and is associated with higher baseline disease activity, more comorbidities, smoking, higher pain and HAQ scores, and increased risk of TNFi treatment discontinuation in a cohort of Danish patients with PsA. The agreement between ACR responses and VASfatigue responses is weak to moderate suggesting heterogeneity between experienced fatigue and joint inflammation.

Acknowledgements: This study was supported by unrestricted grants from The Oak foundation, NordForsk and the DANBIO register.

Disclosure of Interest: T. S. Jørgensen Speakers bureau: Abbvie, Roche, UCB, Novartis, Pfizer, Biogen and Eli Lilly, M. Skougaard: None declared, C. Ballegaard Speakers bureau: Janssen Pharmaceuticals, P. Mease Consultant for: Abbvie, Amgen, BMS, Celgene, Janssen, Lilly, Novartis, Pfizer, SUN, UCB, Speakers bureau: Abbvie, Amgen, BMS, Celgene, Janssen, Novartis, Pfizer, UCB, V. Strand Consultant for: Abbvie, Amgen, BMS, Boehringer Ingelheim, Celltrion, Janssen, Lilly, Merck, Novartis, Pfizer, Samsung, Sandoz, UCB, L. Dreyer Speakers bureau: UCB, MSD, Janssen, L. E. Kristensen Speakers bureau: Pfizer, AbbVie, Amgen, UCB, Celgene, BMS, MSD, Novartis, Eli Lilly, Janssen Pharmaceuticals

DOI: 10.1136/annrheumdis-2018-eular.6780

\section{THU0333 EFFICACY AND SAFETY OF IXEKIZUMAB IN PATIENTS WITH ACTIVE PSORIATIC ARTHRITIS: THREE YEAR RESULTS FROM A PHASE 3 STUDY (SPIRIT-P1)}

${ }^{1}$ V. Chandran, R. Fleischmann ${ }^{2}$, E. Lespessailles ${ }^{3}$, P.S. Helliwell ${ }^{4}$, O. Benichou ${ }^{5}$, J. Erickson ${ }^{5}$, C. Shuler ${ }^{5}$. ${ }^{1}$ Krembil Research Institute, Univ of Toronto, Toronto, Canada; ${ }^{2}$ Metroplex Clinical Research Center, Dallas, USA; ${ }^{3}$ Univ Orléans, Orléans, France; ${ }^{4}$ Univ of Leeds, Leeds, UK; ${ }^{5}$ Eli Lilly and Company, Indianapolis, USA

Background: Ixekizumab (IXE) is a high affinity monoclonal antibody that selectively targets interleukin-17A. IXE, every 4 (Q4W) or 2 (Q2W) weeks, was superior to placebo $(\mathrm{PBO})$ in improving the signs and symptoms of psoriatic arthritis (PsA) at Week 24 in biologic-naïve patients (pts)

Objectives: To determine the efficacy and safety of IXE treatment up to 3 years in biologic-naïve pts with PsA.

Methods: In SPIRIT-P1 (NCT01695239), 381 pts entered the extension period (EP; Weeks 24-156). Pts failing to demonstrate $\geq 20 \%$ improvement in both tender and swollen joint counts at Week 32, or any subsequent visit, were discontinued (mandatory discontinuation criteria). Ad-hoc efficacy data are presented for intent-to-treat (ITT) pts initially randomised to IXE at Week 0. Modified non-responder imputation ( $\mathrm{mNRI}$; missing data treated as non-response for pts discontinued due to lack of efficacy or adverse events [AEs]; multiple imputation (MI) for all other missing data) was applied to categorical measures. Modified baseline observation carried forward (mBOCF) was applied to continuous efficacy measures. Safety assessments are presented for all pts who entered the EP; baseline was the first IXE dose during the EP.

Results: Of the 210 pts initially randomised to IXE at Week 0 (ITT), 125 (60\%) pts completed 156 weeks of treatment; 27 pts discontinued due to AEs, and 26 pts met the mandatory discontinuation criteria. Efficacy results are summarised (table 1). Improvements in ACR (American College of Rheumatology) and PASI (Psoriasis Area and Severity Index) responses, resolution in enthesitis and dactylitis, and improvements from baseline HAQ-DI (Health Assessment Questionnaire Disability Index), enthesitis, and dactylitis persisted up to Week 156 . Safety assessments for all pts who entered the EP are summarised (table 2). Frequencies of treatment-emergent AEs (TEAEs) were similar between IXE Q4W and Q2W. The majority of TEAEs were mild or moderate in severity; serious AEs occurred in 47 pts.

Abstract THU0333 - Table 1. Efficacy Overview at Week 156 (ITT Population)

\begin{tabular}{|c|c|c|}
\hline & IXE Q4W (n=107) & IXE Q2W (n=103 \\
\hline \multicolumn{3}{|c|}{ Responder Rates (n/Nx [\%]): mNRI } \\
\hline ACR20 & $74 / 107$ (69\%) & $64 / 103(62 \%)$ \\
\hline ACR50 & $55 / 107(51 \%)$ & $58 / 103(56 \%)$ \\
\hline ACR70 & $35 / 107$ (33\%) & $45 / 102(44 \%)$ \\
\hline PASI75 ${ }^{\mathrm{a}}$ & $46 / 73(63 \%)$ & $41 / 59(69 \%)$ \\
\hline PASI90 ${ }^{a}$ & $37 / 73(51 \%)$ & $38 / 59(65 \%)$ \\
\hline PASI $100^{\mathrm{a}}$ & $32 / 73(44 \%)$ & $36 / 59(61 \%)$ \\
\hline $\mathrm{LEI}=0^{\mathrm{b}}$ & $32 / 68(47 \%)$ & $23 / 57(40 \%)$ \\
\hline LDI-B $=0^{c}$ & $23 / 37(62 \%)$ & $17 / 25(69 \%)$ \\
\hline \multicolumn{3}{|c|}{ Mean Change from Baseline (SD): mBOCF } \\
\hline HAQ-DI & $-0.4(0.6)$ & $-0.5(0.6)$ \\
\hline $\mathrm{LEI}^{\mathrm{b}}$ & $-1.7(1.8)$ & $-1.7(1.7)$ \\
\hline LDI-B $^{c}$ & $-51.2(91.0)$ & $-55.4(61.3)$ \\
\hline
\end{tabular}

LEI=Leeds Enthesitis Index; LDI-B=Leeds Dactylitis Index-Basic; Nx=pts with non-missing data; $\mathrm{n}=$ responders. With $\mathrm{mNRI}$, missing data were treated as nonresponse for pts discontinued due to lack of efficacy or AEs. All other missing data were imputed with MI. With MI analysis, 32 patients were considered ACR20 res ponders. a Pts with psoriatic lesions ${ }^{3} 3 \%$ of body surface area at baseline. ${ }^{\mathrm{b}} \mathrm{Pts}$ with $\mathrm{LEI}>0$ at baseline. ${ }^{\mathrm{C}} \mathrm{Pts}$ with $\mathrm{LDI}-\mathrm{B}>0$ at baseline.

Abstract THU0333 - Table 2. Safety Outcome Measures (Weeks 24-156)

\begin{tabular}{|c|c|c|}
\hline & Total IXE Q4W ( $N=191)$ & Total IXE Q2W (N=190) \\
\hline TEAEs & $146(76 \%)$ & $144(76 \%)$ \\
\hline Serious AEs & $28(15 \%)$ & $19(10 \%)$ \\
\hline Serious Infections & $5(3 \%)$ & $1(<1 \%)$ \\
\hline \begin{tabular}{|l} 
Discontinued due to $\mathrm{AE}$ \\
\end{tabular} & $16(8 \%)$ & $21(11 \%)$ \\
\hline \begin{tabular}{|l} 
Death \\
\end{tabular} & $1^{\circ}(<1 \%)$ & 0 \\
\hline \begin{tabular}{|l} 
Infections \\
\end{tabular} & $92(48 \%)$ & $94(49 \%)$ \\
\hline \begin{tabular}{|l} 
Injection-Site Reactions \\
\end{tabular} & $21(11 \%)$ & $23(12 \%)$ \\
\hline \begin{tabular}{|l} 
Hypersensitivities \\
\end{tabular} & $8(4 \%)$ & $11(6 \%)$ \\
\hline
\end{tabular}

Conclusions: In pts treated with IXE, improvements in the signs and symptoms of PsA persisted up to 3 years. No unexpected safety signals were observed, and the safety profile was consistent with previous studies of IXE.

Disclosure of Interest: V. Chandran Grant/research support from: Abbvie, Consultant for: Abbvie, Amgen, Celgene, Eli Lilly and Company, Janssen, Novartis, Pfizer, UCB, R. Fleischmann Consultant for: AbbVie, Acea, Amgen, Bristol-Myers Squibb, Eli Lilly and Company, Novartis, Pfizer, Sanofi-Aventis, and UCB, E. Lespessailles Grant/research support from: Novartis, Eli Lilly and Company, Servier, and Amgen, Speakers bureau: Novartis, Eli Lilly and Company, P. Helliwell Grant/research support from: AbbVie, Amgen, Bristol-Myers Squibb, Celgene, Eli Lilly and Company, Janssen, Merck, Novartis, and UCB, O. Benichou Shareholder of: Eli Lilly and Company, Employee of: Eli Lilly and Company, J. Erickson Shareholder of: Eli Lilly and Company, Employee of: Eli Lilly and Company, C. Shuler Shareholder of: Eli Lilly and Company, Employee of: Eli Lilly and Company DOI: 10.1136/annrheumdis-2018-eular.2137

THURSDAY, 14 JUNE 2018

\section{SLE, Sjögren's and APS - clinical aspects (other than treatment)}

\section{THU0334 PATTERNS OF ASPIRIN USE IN SLE PREGNANCIES WITHIN A MULTINATIONAL INCEPTION COHORT AND RELATIONSHIP TO PREECLAMPSIA RISK FACTORS}

A. Mendel, S. Bernatsky, E. Vinet, on behalf of SLICC Investigators. McGill University, Montreal, Canada

Background: Aspirin reduces the risk of preeclampsia in pregnancies at high risk, and is recommended in pregnant women with $\geq 1$ risk factors for preeclampsia, including systemic lupus erythematosus (SLE)

Objectives: To assess the prevalence of aspirin use in SLE pregnancies within a multinational inception cohort and compare aspirin use among those with and without additional preeclampsia risk factors.

Methods: Premenopausal women aged 18-45 enrolled in the Systemic Lupus International Collaborating Clinics (SLICC) Registry (2000-2017) within 15 